\title{
Malignant tumor is the greatest risk factor for pulmonary embolism in hospitalized patients: a single-center study
}

Kaoru Fujieda ${ }^{1,2^{*}}$ (D, Akiko Nozue ${ }^{1}$, Akie Watanabe ${ }^{1,2}$, Keiko Shi ${ }^{1,2}$, Hiroya Itagaki ${ }^{2}$, Yoshihiko Hosokawa ${ }^{2}$, Keiko Nishida ${ }^{2}$, Nobutaka Tasaka ${ }^{2}$, Toyomi Satoh ${ }^{2}$ and Ken Nishide ${ }^{1}$

\begin{abstract}
Background: This study aimed to investigate the background of patients who presented with pulmonary embolism (PE) on contrast-enhanced chest computed tomography (CT) and to explore the risk factors for PE.

Methods: This study included a review of the medical records of all 50,621 patients who were admitted to one community hospital between January 1, 2013 and December 31, 2017. Data on sex, age, risk factors related to blood flow stagnation (obesity, long-term bed rest, cardiopulmonary disease, cast fixation, long-term sitting), risk factors related to vascular endothelial disorder (surgery, trauma/fracture, central venous catheterization, catheter tests/treatments, vasculitis, antiphospholipid antibody syndrome, history of venous thromboembolism (VTE)), and risk factors related to hypercoagulability (malignant tumor, use of oral contraceptives/low-dose estrogen progestin/ steroids, infection, inflammatory enteric disease, polycythemia, protein C or protein S deficiency, dehydration) were evaluated.
\end{abstract}

Results: Of all inpatients, 179(0.35\%) out of 50,621 were diagnosed with PE after contrast-enhanced chest CT examination, in which 74 patients were symptomatic and 105 patients had no symptom. Among asymptomatic 105 patients, 71 patients got CT scans for other reasons including cancer screening and searching infection focus, and 34 patients got $\mathrm{CT}$ scans for searching PE due to either apparent or suspicious DVT. The rate of discovering PE was significantly greater in women $(0.46 \%, 90 / 19,409)$ than men $(0.29 \%, 89 / 31,212)(P=0.008)$. Of the 179 patients with PE, 164 (92\%) had some type of risk factor. For both men and women, the most frequent risk factor was a malignant tumor, followed by obesity, long-term bed rest and infection for men and long-term bed rest, obesity and infection for women. The most common malignant tumor was lung cancer. Although taking antipsychotic agent is not advocated as a risk factor, there is a possibility of involvement.

Conclusions: The risk factors for PE were identified in this single-center, retrospective study.

Keywords: Venous thromboembolism, Pulmonary embolism, Gynecological cancer

\footnotetext{
* Correspondence: fujieda-smr@umin.ac.jp

${ }^{1}$ Tsukuba Medical Center Hospital, Tsukuba, Ibaraki, Japan

${ }^{2}$ Department of Obstetrics and Gynecology, Faculty of Medicine, University

of Tsukuba, 1-1-1 Tennoudai, Tsukuba, Ibaraki 305-8575, Japan
} 


\section{Background}

The mortality of patients who develop acute pulmonary embolism (PE) is high, at 4.1-14.5\% [1-3], indicating the seriousness of the condition. The mechanism of onset is as follows: first, the free-floating blood clots formed in the deep vein or right atrium rapidly occlude the pulmonary artery, and over $90 \%$ of the cases are caused by deep vein thrombosis (DVT) formed in the lower limbs or pelvis [4, 5]. Factors that cause venous thromboembolism (VTE), as proposed by Virchow in 1856 are (1) blood flow stagnation, (2) vascular endothelial disorder, and (3) hypercoagulability [6]. Numerous underlying conditions affect the onset of PE, and PE occurs in patients admitted to various departments. However, most reports of PE in Japan include cases from only a single department. This study aimed to investigate the background of patients who presented with PE on contrast-enhanced chest computed tomography (CT) and to explore the risk factors for PE.

\section{Methods \\ Patients}

This study included all 50,621 patients who were admitted to the Tsukuba Medical Center Hospital between January 1, 2013 and December 31, 2017. Because we used the records of hospitalized patients, same patients who admitted to hospital another period were counted separately.

\section{Diagnosis of PE}

PE was diagnosed after contrast-enhanced chest CT examination. There was no algorithm for diagnosing $\mathrm{PE}$ in our hospital. The condition of CT scanning was not unified, but there was possibility of PE or DVT, we used specific condition CT to find a VTE. After injection of a contrast medium, we scanned chest $15-20 \mathrm{~s}$ later and lower limbs $3 \mathrm{~min}$ later.

\section{Examination medical records}

A retrospective examination of medical records was conducted to extract data on sex, age, risk factors related to blood flow stagnation (obesity, long-term bed rest, cardiopulmonary disease, cast fixation, long-term sitting), risk factors related to vascular endothelial disorder (surgery, trauma/fracture, central venous catheterization, catheter tests/treatments, vasculitis, antiphospholipid antibody syndrome, history of VTE), and risk factors related to hypercoagulability (malignant tumor, use of oral contraceptives/low-dose estrogen progestin/steroids, infection, inflammatory enteric disease, polycythemia, protein $\mathrm{C}$ or protein $\mathrm{S}$ deficiency, dehydration). For patients with multiple risk factors, each factor was counted separately for the analysis. For patients with a malignant tumor, the frequency of $\mathrm{PE}$ was calculated by cancer type. The $\chi^{2}$ test was used for analysis, and $P<0.05$ was considered significant.

\section{Summary of facilities}

Our hospital is a 453-bed community hospital primarily equipped to handle emergency medicine. Emergency admission to the cardiology and neurology departments is relatively common, and perinatal conditions are not handled. This study was approved by the institutional review board at Tsukuba Medical Center Hospital.

\section{Results}

Patients' profile: symptomatic and asymptomatic, association with DVT

Of all inpatients, $179(0.35 \%)$ out of 50,621 were diagnosed with PE after contrast-enhanced chest CT examination, in which 74 patients were symptomatic and 105 patients had no symptom. Among asymptomatic 105 patients, 71 patients got CT scans for other reasons including cancer screening and searching infection focus, and 34 patients got CT scans for searching PE due to either apparent or suspicious of DVT. 74 patients had symptoms such as dyspnea, chest pain, fever, fainting, cough, wheezing, hemoptysis and palpitations [7]. 74 symptomatic patients and 34 asymptomatic patients (31 had lower limb edema and 3 had proximal DVT) were made CT scanning for a suspicious of PE. 5 symptomatic patient's vital signs were deadly, took only chest CT scan immediately. In asymptomatic patients, 4 patients with lower limb edema and 3 patients with elevated D-dimmer value were made lower limb ultrasonography prior to CT scan and had proximal DVT. Left 27 patients with lower limb edema searched for DVT by CT scan, 25 patients had DVT. 71 patients got a CT scan for other reasons and diagnosed PE coincidentally. 48 out of 71 patients searched for DVT and 31 had DVT. (Figs. 1,2).

PE was more proximal pulmonary artery than subregion branch in all patients. However, there was possibility of overlooking peripheral PE because it was not routine work to search the PE in asymptomatic patient.

\section{Gender and age}

The rate of discovering $\mathrm{PE}$ was significantly greater in women $(0.46 \%, 90 / 19,409)$ than men $(0.29 \%, 89 / 31,212)$ $(P=0.008)$. Table 1 show the number of patients with $\mathrm{PE}$ by sex and age group.

In men, the number of patients increased gradually from the 30s age group and reached a peak around the $60-70$ s age group. In contrast, in women, the number increased from the $40 \mathrm{~s}$ age group, with a relatively steep peak at the 70-80s age group. In men, the rate of discovering PE was not different between those under age 60 years $(0.32 \%, 37 / 11,609)$ and those 60 years and older $(0.27 \%, 52 / 19,603)(P=0.3)$. In contrast, in women, the 
74 were symptomatic $\mathrm{PE}$

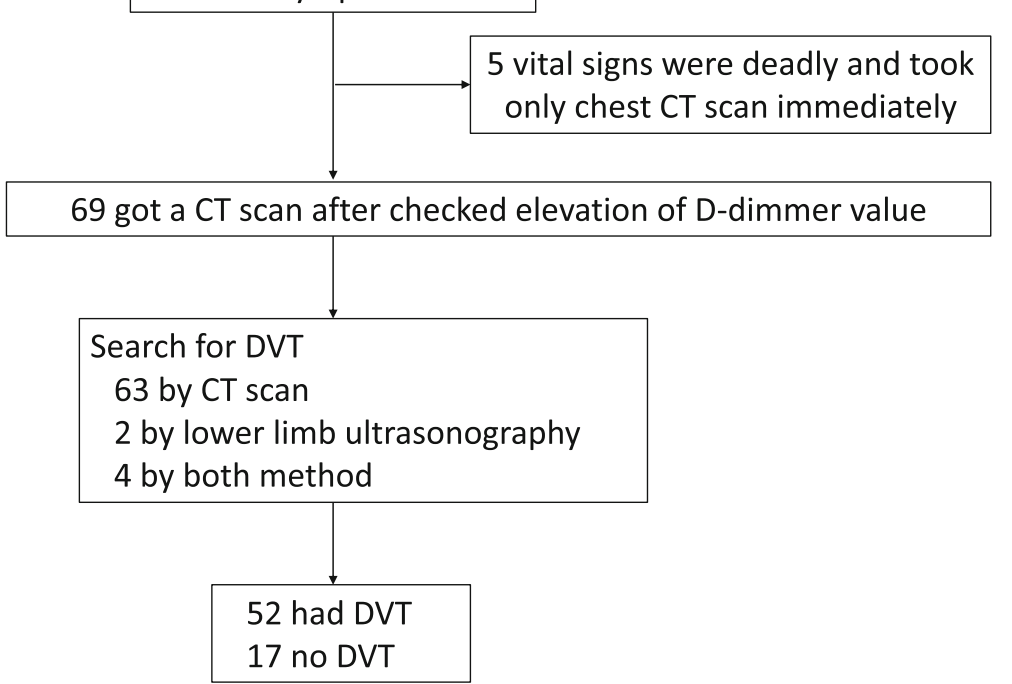

Fig. 1 Screening method of symptomatic PE patients

rate was significantly greater in those 60 years and older $(0.63 \%, 69 / 11,009)$ than in those under 60 years of age $(0.25 \%, 21 / 8400)(P=0.0001)$.

\section{Risk factors for DVT/PE}

Of the 179 patients with PE, 164 (92\%) had some type of risk factor (Table 2).

There was difference in the frequency of CT scanning between cancer and other diseases. 1 patient with colon cancer or lung cancer got a CT scan every 3 months, 1 patient with lung cancer got a CT scan every 6 months after the treatment. 8 cancer patients $(6$ patients with lung cancer, 1 patient with colon cancer, 1 patient with breast cancer) who were under the treatment got a CT scan every time judging the therapeutic effect. Other cancer patients got a CT scan one time only to investigate the causes of symptoms. Other than cancer patients, 17 patients got a second time CT scan, because 6 patients had hypoxia, 6 patients suspected DVT, 5 patients followed up trauma or infection. Other patients got a CT scan one time only.

We used Wells score and defined that long-term bed rest was more than $72 \mathrm{~h}[8]$ and sitting for a long time was more than $5 \mathrm{~h}$ [9]. 22 out of 41 patients, long-term

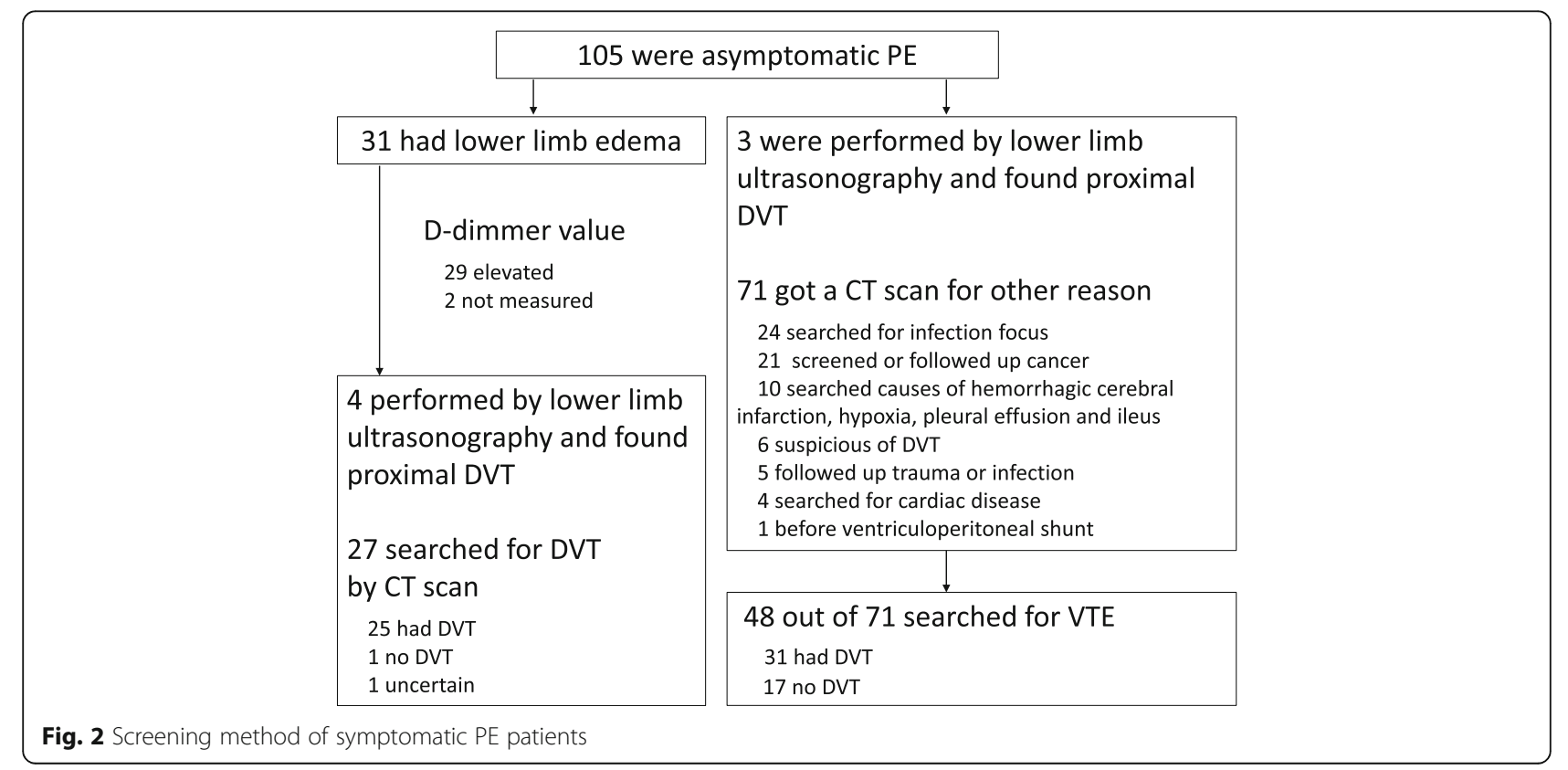


Table 1 Distribution of the number of patients by age and sex

\begin{tabular}{lll}
\hline Age(y) & Male(\%) & Female(\%) \\
\hline $10-19$ & $1(1)$ & $0(0)$ \\
$20-29$ & $1(1)$ & $1(1)$ \\
$30-39$ & $8(9)$ & $2(2)$ \\
$40-49$ & $13(15)$ & $7(8)$ \\
$50-59$ & $14(16)$ & $11(12)$ \\
$60-69$ & $18(20)$ & $15(17)$ \\
$70-79$ & $17(19)$ & $28(31)$ \\
$80-89$ & $13(15)$ & $22(24)$ \\
$90-99$ & $4(4)$ & $4(4)$ \\
\hline
\end{tabular}

bed rest was in-hospital outbreak. They were forced long-term bed rest due to consciousness or trauma.

Regarding to surgery, trauma/fracture and central venous catheterization, refer to Wells score, we determined that the time was less than 3 months before admission. The median time to onset, $10(0-60)$ days at operation, 10 (0-72) days at trauma, fracture and cast fixed, and 8 days at central venous catheter. 1 patient after operation of osteoarthritis of the knee had 60 days, 2 patients after fractured had 17 days or 60 days before administration, other patients were admitted immediately after injured or already in the hospital to get surgery.

Only one patient who had past medical history of VTE took anticoagulant therapy, warfarin, other patients were self-interruption or not prescribed.
Patients for unknown reason were measured thrombus predisposition (Protein $\mathrm{C}$ or $\mathrm{S}$, anti-cardiolipin antibody and lupus anti-core grant), and 2 patients were diagnosed protein $\mathrm{C}$ or $\mathrm{S}$ deficiency, 1 patient was diagnosed antiphospholipid antibody syndrome.

The risk factor for the development of PE could not be identified in 15 patients.

Although taking antipsychotic agent is not advocated as a risk factor, 9 patients with schizophrenia were taking antipsychotic agent.

\section{Gender difference}

Although there were no significant differences between men and women in the percentage of patients with each PE risk factor, long-term bed rest was more common in women, at $17 \%$, compared with men, at $13 \%$, and trauma/fracture/cast fixation was more common in men, at $8 \%$, than in women, at $6 \%$. A total of $33(89 \%)$ obese patients had another risk factor. For both men and women, the most frequent risk factor was a malignant tumor, followed by long-term bed rest and infection.

\section{Contribution of cancer-bearing}

47 patients with PE and a malignant tumor. 35 patients had advanced cancer. 27 patients were diagnosed cancer after PE diagnosis. Seventeen patients were under the treatment (15 patients had chemotherapy, 1 patient had hormone therapy, 1 patient had surgery). Ten out of 17

Table 2 The risk factors of patients with PE separated by gender

\begin{tabular}{|c|c|c|c|c|}
\hline & Risk factor & Male(\%) & Female(\%) & $P$-value \\
\hline \multirow[t]{7}{*}{ Blood flow stagnation } & Obesity & $20(15)$ & $17(13)$ & 0.63 \\
\hline & Long-term bed rest & $18(13)$ & $23(17)$ & 0.37 \\
\hline & Sitting for a long time & $3(2)$ & $4(3)$ & 0.69 \\
\hline & Cardiopulmonary disease & $4(3)$ & $7(5)$ & 0.34 \\
\hline & Trauma, Fracture, Cast fixed & $11(8)$ & $8(6)$ & 0.50 \\
\hline & Central venous catheter & $0(0)$ & $1(1)$ & 0.31 \\
\hline & Surgery & $9(7)$ & $9(7)$ & 0.97 \\
\hline \multirow[t]{3}{*}{ Vascular endothelial disorder } & Antiphospholipid antibody syndrome and collagen disease & $6(4)$ & $2(1)$ & 0.16 \\
\hline & Past medical history of VTE & $2(1)$ & $1(1)$ & 0.57 \\
\hline & Cancer & $24(18)$ & $23(17)$ & 0.92 \\
\hline \multirow[t]{7}{*}{ Hypercoagulability } & OCs, LEP, Steroids & $2(1)$ & $5(4)$ & 0.24 \\
\hline & Infection & $18(13)$ & $17(13)$ & 0.89 \\
\hline & Inflammatory enteric disease & $1(1)$ & $2(1)$ & 0.55 \\
\hline & Polycythemia & $1(1)$ & $1(1)$ & 0.99 \\
\hline & Protein $\mathrm{C}$ or Protein $\mathrm{S}$ deficiency & $2(1)$ & $0(0)$ & 0.16 \\
\hline & Dehydration & $4(3)$ & $6(5)$ & 0.50 \\
\hline & No risk factor & $9(7)$ & $6(5)$ & 0.44 \\
\hline
\end{tabular}


patients who were under the treatment got a CT scan to judge therapeutic effect, 7 patients were PD, 2 patients were PR, 1 patient was SD. 3 patients got a CT scan regularly to follow up after treatment and 1 patient had seen recurrence of cancer. 45 patients (95\%) had active cancer.

Patients with lung cancer were the most common, accounting for $34 \%$ of the 47 patients. The rate of discovering PE by cancer type was greatest in ovarian cancer, at $3.3 \%$, followed by endometrial cancer, at $2.4 \%$ (Table 3 ).

The rate of discovering PE in ovarian cancer was not significantly different from that of endometrial cancer, gallbladder cancer, and lung cancer, but it was significantly greater compared with that of colon cancer, stomach cancer, breast cancer, prostate cancer, kidney cancer, and cervical cancer ( $P=0.0001$ to 0.01$)$.

\section{Discussion}

Although there are conflicting reports that the incidence of $\mathrm{PE}$ is higher in men $[10,11]$ or is not different between men and women [12], the incidence is 1.5-fold higher in Japanese women than men, peaking in the 60 70s age group [13]. The present results also showed that the discovery rate was greater in women and peaked around the 60-70s, corroborating previous reports from Japan. PE is thought to more likely occur in older individuals than in younger individuals because the morbidity of underlying conditions, such as cerebrovascular disease/neurological disease, long-term bed rest from a lumbar compression fracture, malignant tumor, and bacterial infections including aspiration pneumonia/pyelonephritis, that are likely to cause VTE increases with increasing age. In particular, in postmenopausal women, events such as cardiovascular diseases and fractures increase rapidly, and this is considered to be the reason why PE is frequently observed in older women.

In PE patients with a malignant tumor, lung cancer was the most common tumor. This is because patients with lung cancer are the most common cancer inpatients at our hospital, and because smoking, a risk factor for lung cancer [14], is also a risk factor for VTE [15]. Thus, this was an expected outcome. Analysis of the PE discovery rate by cancer type showed that patients with ovarian cancer had the highest rate. Before treatment, PE was discovered in $8.8-13.3 \%$ of ovarian cancer [16, 17], 3.0-4.7\% of endometrial cancer [16, 18], $1.1-1.4 \%$ of cervical cancer $[16,19]$, and $2.9 \%$ of advanced pancreatic cancer [20] cases. Moreover, whereas $\mathrm{PE}$ was not discovered in bladder cancer or stomach cancer cases, DVT was found in 13.9 and $4.4 \%$ of the patients, respectively [21]. VTE is common in ovarian cancer due to vascular dehydration caused by ascites [16] and venous compression by a large tumor [22]. In clear cell carcinoma, Factor VII is activated via the extrinsic blood coagulation pathway, leading to the production of tissue factors that augment coagulation [23, 24], and this is thought to be one of the causes for high VTE rates.

Although taking antipsychotic agent was not advocated as a risk factor, there was a possibility of involvement. Antipsychotics are known to induce pulmonary vasospasm and contraction, as well as platelet aggregation via the serotonin-like action of 5HT2/D2 antagonists [25]. Taking antipsychotics for more than 24 months increases the risk for VTE by $32 \%$, and by $73 \%$ with atypical antipsychotics [26]. In Japan, the Ministry of Health, Labour and Welfare in 2010 recommended the addition of PE and DVT as serious side effects to the package inserts of antipsychotics such as haloperidol, blonanserin, clozapine, and risperidone. The use of antipsychotics should perhaps be noted as a risk factor for VTE.

\section{Conclusions}

In our hospital, the rate of discovering PE was high in women who were at least 60 years old. In $92 \%$ of the cases, some type of risk factor for onset was identified. The most frequently observed risk factor was a malignant tumor. Lung cancer was the most common by the number of patients, and ovarian cancer was the highest

Table 3 Numbers and incidence of patients with PE by each cancer type

\begin{tabular}{lll}
\hline Cancer type & Number of hospitalized patients & Number of patients with PE(\%) \\
\hline Ovarian cancer & 152 & $5(3.3)$ \\
Endometrial cancer & 122 & $3(2.4)$ \\
Gallbladder cancer & 89 & $2(2.2)$ \\
Lung cancer & 1258 & $16(1.3)$ \\
Colon cancer & 1177 & $9(0.8)$ \\
Gastric cancer & 693 & $3(0.4)$ \\
Breast cancer & 1109 & $5(0.5)$ \\
Prostate cancer & 881 & $3(0.3)$ \\
Kidney cancer & 816 & $1(0.1)$ \\
Cervical cancer & 287 & $0(0)$ \\
\hline
\end{tabular}


by frequency of discovery. Other risk factors were infection, long-term bed rest and obesity. $89 \%$ of obese patients had another risk factor. Antipsychotic drugs may have been associated with PE in some patients.

There are some limitations of this study. Firstly, the sample size is small. 179 patients were selected, but the number of patients would not be sufficient to collect relevant date. Secondly, patients had some risk factors, so we couldn't declare the most influence risk factors. Finally, there was limitation of department in our hospital, therefore there was the possibility of overlooking the risk factor or undiagnosed diseases. Furthermore, we were unable to fully analyze the date of patients who had not PE, because some medical records were disposed, so we couldn't do multivariate analysis.

Though there are limitations with this single-center retrospective study, it demonstrated the risk factors for $\mathrm{PE}$ in patients who presented with PE.

\section{Abbreviations}

PE: Pulmonary embolism; CT: Computed tomography; VTE: Venous thromboembolism; DVT: Deep vein thrombosis; BMI: Body mass index; OCs: Oral contraceptives; LEP: Low dose Estrogen Progestin; RECIST: Response evaluation criteria in solid tumors; NED: No evidence of disease; Rec: Recurrence; PD: Progressive disease; SD: Stable disease; PR: Partial response

\section{Authors' contributions}

AN, KF and NK were involved in study design and date interpretation. AN, KF, NK and TS were involved in the date analysis. All authors read and approved the final manuscript.

\section{Funding}

This work was supported by JSPS KAKENHI Grant Number JP18K09218 Grantin-aid for Scientific Research (C).

\section{Availability of data and materials}

The datasets used and/or analyzed during the current study are available from the corresponding author on reasonable request.

\section{Declarations}

\section{Ethics approval and consent to participate}

This study was approved by the institutional review board at Tsukuba Medical Center Hospital.

\section{Consent for publication}

Not applicable.

\section{Competing interests}

The authors declare that they have no competing interests.

Received: 16 December 2020 Accepted: 19 October 2021 Published online: 30 October 2021

\section{References}

1. Akgüllü Ç, Ömürlü IK, Eryılmaz U, Avcil M, Dağtekin E, Akdeniz M, et al. Predictors of early death in patients with acute pulmonary embolism. Am J Emerg Med. 2015;33(2):214-21. https://doi.org/10.1016/j.ajem.2014.11.022.

2. Becattini C, Agnelli G, Mareike L, Masotti L, Pruszczyk P, Casazza F, et al. Acute pulmonary embolism: mortality prediction by the 2014 European Society of Cardiology risk stratification model. Eur Respir J. 2016;48(3):780-6. https://doi.org/10.1183/13993003.00024-2016.

3. Bach AG, Taute BM, Baasai N, Wienke A, Meyer HJ, Schramm D, et al. 30-day mortality in acute pulmonary embolism: prognostic value of clinical scores and anamnestic features. PLoS One. 2016;11(2):e0148728. https://doi.org/1 0.1371/journal.pone.0148728.

4. Moser KM. Venous thromboembolism. Am Rev Respir Dis. 1990;141(1):23549. https://doi.org/10.1164/ajrccm/141.1.235.

5. Ro A, Kageyama N, Tanifuji T, Fukunaga T. Pulmonary thromboembolism: overview and update from medicolegal aspects. Leg Med (Tokyo). 2008; 10(2):57-71. https://doi.org/10.1016/j.legalmed.2007.09.003.

6. Virchow R. Gesammalte Abhandlungen Zur Wissenschaftlichen Medizin. Frankfurt: Medinger Sohn \& CO; 1856. p. 219-732.

7. Maisso M, Renato P, Brouno F, Carlo M, Giorgio DR, Lucia T, et al. Accuracy of clinical assessment in the diagnosis of pulmonary embolism. Am J Respir Crit Care Med. 1999;159(3):864-71.

8. Wells PS, Owen C, Doucette S, Fergusson D, Tran H. Dose this patient have deep vein thrombosis? JAMA. 2006;295(2):199-207. https://doi.org/10.1001/ jama.295.2.199.

9. Shirakawa T, Iso H, Yamagishi K, Yatsuya H, Tanabe N, Ikehara A, et al. Watching television and risk of mortality from pulmonary embolism among Japanese men and women: the JACC study (Japan collaborative cohort). Circulation. 2016;134(4):355-7. https://doi.org/10.1161/CIRCULATIONAHA.11 6.023671.

10. Naess IA, Christiansen SC, Romundstad P, Cannegieter SC, Rosendaal FR, Hammerstrøm J. Incidence and mortality of venous thrombosis: a population-based study. J Thromb Haemost. 2007;5(4):692-9. https://doi. org/10.1111/j.1538-7836.2007.02450.x.

11. Heit JA. The epidemiology of venous thromboembolism in the community. Arteriosclerosis Thromb Vasc Biol. 2008;28(3):370-2. https://doi.org/10.11 61/ATVBAHA. 108.162545

12. Nordström $M$, Lindblad $B$, Bergqvist $D$, Kjellström $T$. A prospective study of the incidence of deep-vein thrombosis within a defined urban population. $J$ Intern Med. 1992;232(2):155-60. https://doi.org/10.1111/j.1365-2796.1992. tb00565.x.

13. Nakamura M, Fujioka H, Yamada N, Sakuma M, Okada O, Nakanishi N, et al. Clinical characteristics of acute pulmonary thromboembolism in Japan: results of a multicenter registry in the Japanese Society of Pulmonary Embolism Research. Clin Cardiol. 2001;24(2):132-8. https://doi.org/10.1002/ clc.4960240207.

14. Sobue T, Yamamoto S, Hara M, Sasazuki S, Sasaki S, Tsugane S. Cigarette smoking and subsequent risk of lung cancer by histologic type in middleaged Japanese men and women: the JPHC study. Int J Cancer. 2002;99(2): 245-51. https://doi.org/10.1002/ijc.10308.

15. Cheng YJ, Liu ZH, Yao FJ, Zeng WT, Zheng DD, Dong YG, et al. Current and former smoking and risk for venous thromboembolism: a systematic review and meta-analysis. PLoS Med. 2013;10(9):e1001515. https://doi.org/10.1371/ journal.pmed.1001515.

16. Kodama J, Seki N, Fukushima C, Kusumoto T, Nakamura K, Hongo A, et al. Elevated preoperative plasma D-dimer levels and the incidence of venous thromboembolism in Japanese females with gynecological cancer. Oncol Lett. 2013;5(1):299-304. https://doi.org/10.3892/ol.2012.970.

17. Satoh T, Oki A, Uno K, Sakurai M, Ochi H, Okada S, et al. High incidence of silent venous thromboembolism before treatment in ovarian cancer. $\mathrm{Br} J$ Cancer. 2007;97(8):1053-7. https://doi.org/10.1038/sj.bjc.6603989.

18. Satoh T, Oki A, Uno K, Sakurai M, Ochi H, Okada S, et al. Silent venous thromboembolism before treatment in endometrial cancer and the risk factors. Br J Cancer. 2008;99(7):1034-9. https://doi.org/10.1038/sj.bjc.6604658.

19. Satoh T, Matsumoto K, Tanaka YO, Akiyama A, Nakao S, Sakurai M, et al. Incidence of venous thromboembolism before treatment in cervical cancer and the impact of management on venous thromboembolism after commencement of treatment. Thromb Res. 2013;131(4):127-32. https://doi. org/10.1016/j.thromres.2013.01.027.

20. Kondo S, Sakai M, Hosoi H, Sakamoto Y, Morizane C, Ueno H, et al. Incidence and risk factors for venous thromboembolism in patients with pretreated advanced pancreatic carcinoma. Oncotarget. 2018;9(24):1688390. https://doi.org/10.18632/oncotarget.24721.

21. Schomburg JL, Krishna S, Cotter KJ, Soubra A, Rao A, Konely BR. Preoperative incidence of deep venous thrombosis in patients with bladder cancer undergoing radical cystectomy. Urology. 2018;116:120-4. https://doi. org/10.1016/j.urology.2018.01.052.

22. Liao TY, Hsu HC, Wen MS, Juan YH, Hung YH, Liaw CC. Iliofemoral venous thrombosis mainly related to iliofemoral venous obstruction by external tumor compression in cancer patients. Case Rep Oncol. 2016;9(3):760-71. https://doi.org/10.1159/000452943. 
23. Uno K, Homma S, Satoh T, Nakanishi K, Abe D, Matsumoto K, et al. Tissue factor expression as a possible determinant of thromboembolism in ovarian cancer. Br J Cancer. 2007;96(2):290-5. https://doi.org/10.1038/sj.bjc.6603552.

24. Chanakira A, Westmark PR, Ong IM, Sheehan JP. Tissue factor-factor VIla complex triggers protease activated receptor 2-dependent growth factor release and migration in ovarian cancer. Gynecol Oncol. 2007;145(1):167-75.

25. Boullin DJ, Woods HF, Grimes RP, Grahame-Smith DG. Increased platelet aggregation responses to 5 -hydroxytryptamine in patients taking chlorpromazine. Br J Clin Pharmacol. 1975;2(1):29-35. https://doi.org/1 0.1111/j.1365-2125.1975.tb00468.x.

26. Parker C, Coupland C, Hippisley-Cox J. Antipsychotic drugs and risk of venous thromboembolism: nested case-control study. BMJ. 2010;341(sep21 1):c4245. https://doi.org/10.1136/bmj.c4245.

\section{Publisher's Note}

Springer Nature remains neutral with regard to jurisdictional claims in published maps and institutional affiliations.

Ready to submit your research? Choose BMC and benefit from:

- fast, convenient online submission

- thorough peer review by experienced researchers in your field

- rapid publication on acceptance

- support for research data, including large and complex data types

- gold Open Access which fosters wider collaboration and increased citations

- maximum visibility for your research: over $100 \mathrm{M}$ website views per year

At BMC, research is always in progress.

Learn more biomedcentral.com/submissions 